\title{
On the Castability of Corrosion Resistant DS-Superalloys
}

\author{
J. Rösler, M. Konter* and C. Tönnes \\ ABB Power Generation Ltd., Baden, Switzerland \\ *ABB Corporate Research, Baden, Switzerland
}

\section{Introduction}

In the past it has been well established that DS versions of conventional, corrosion resistant superalloys such as IN792 often suffer from poor castability. Main issues are insufficient resistance against grain boundary (GB) cracking, freckle formation, equiaxed grain formation and a negative heat treatment window which can impair the strength advantage over the conventionally cast counterpart. This highlights the need for compositions that are specifically tailored for DS-applications.

One compositional modification to avert grain boundary cracking, which is a consequence of shrinkage stresses during casting, is the addition of Hafnium /1, 4/. However, Hf-addition has some drawback by itself especially when large castings for stationary gas turbine applications are considered. It not only reduces the heat treatment window (temperature difference between incipient melting point and $\gamma$ '-solvus), but also increases the reactivity of the alloy with the shell mould which can lead to wrinkle formation and inclusions. Compositional changes that improve GBcracking resistance without addition of $\mathrm{Hf}$ are therefore particularly attractive

For the above reason, it is the goal of this paper to investigate measures for DS-castability improvement in non-Hf containing superalloys. Furthermore, the focus is on materials with $\mathrm{Cr}$-content in the $12 \%$ range which yields acceptable resistance in corrosive environments along with an attractive strength potential. After investigating fundamental aspects of DS-castability on model alloys in the first part, expcrience with alloy $A B B$ 2 DS is reported in the second part. This alloy has been developed along the lines proposed here. For comparison, reference is also made to well established "low-Cr" DSalloys such as CM247LC DS.

\section{Fundamental aspects of DS-castability}

\section{Grain boundary cracking}

Grain boundary cracking is frequently encountered during casting of hollow DS-blades. It is a consequence of shrinkage stresses between superalloy and ceramic core and is believed to occur at temperatures close to the melting point /4/ ("hot tearing"). To assess the mechanism of $\mathrm{GB}$ cracking, cylindrical DS-specimens were subjected to compressive loading along the longitudinal axis in a Gleeble 1500 testing machine 15/. Tests were performed in vacuum at temperatures between $1100^{\circ} \mathrm{C}$ and $1250^{\circ} \mathrm{C}$. The specimens were heated by electric resistance heating. All specimens were tested in the as-cast condition unless otherwise stated. Measuring the specimen diameter $D$, the circumferential tensile strain acting perpendicular to the grain boundaries is given by

$$
\varepsilon=\frac{\mathrm{D}}{\mathrm{D}_{0}}-1
$$

$\left(D_{0}\right.$ : initial specimen diameter). In fig. $1 \varepsilon_{\text {crit, }}$, which is defined as the circumferential strain at first crack occurrence, is plotted as a function of temperature. The composition of the investigated model compositions is given in tab. I. A remarkable finding is that the fracture strain strongly decreases towards higher temperatures above approx. $1150^{\circ} \mathrm{C}$. This is consistent with the notion of "hot tearing" as the relevant fracture mechanism. Furthermore, $\varepsilon_{\text {crit }}$ is strongly composition dependent. For Var. a, a circumferential strain of approximately $2 \%$ is sufficient for $\mathrm{GB}$ cracking to occur at $1250^{\circ} \mathrm{C}$. In contrast, Var. b and CM247LC DS, which is known for its GB cracking resistance, endure approximately $10 \%$ strain before fracture. The major difference between Var. a and Var. $b$ is the substitution of $\gamma / \gamma^{\prime}$-eutectic forming elements by tungsten. 
Table I Nominal composition of investigated model alloys

\begin{tabular}{|l|l|l|l|l|l|l|l|l|l|}
\hline Alloy & $\mathrm{Ni}$ & $\mathrm{Co}$ & $\mathrm{Cr}$ & W & $\mathrm{Al}$ & $\mathrm{Ti}$ & $\mathrm{Ta}$ & $\mathrm{B}$ & $\mathrm{C}$ \\
\hline Var. a & bal. & 9.0 & 12.0 & 6.0 & 4.0 & 3.6 & 4.8 & 0.015 & 0.07 \\
\hline Var. b & bal. & 9.0 & 12.0 & 9.0 & 3.5 & 2.3 & 5.5 & 0.015 & 0.07 \\
\hline
\end{tabular}

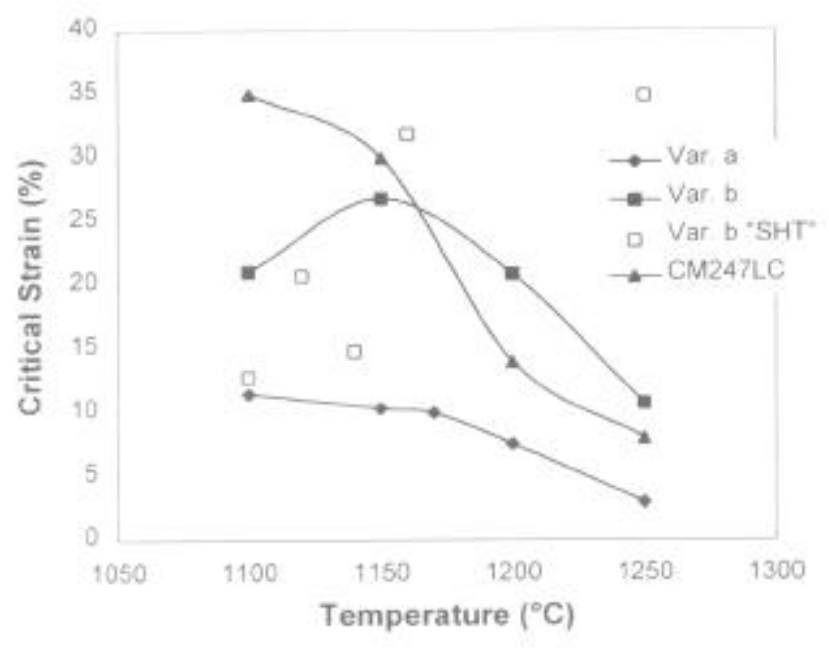

Figure 1: Plot of the critical circumferential strain to fracture, $E_{c r k}$. as a function of test temperature All materials are tested in the as-cast condition unless otherwise stated ("SHT": solution heat treatment).

To further clanify the microstructural factors responsible for the resistance against GB cracking. Var. b was $100 \%$ solution heat treated and retested (fig. 1). Note, that ductility is now increasing with temperature At $1250^{\circ} \mathrm{C}$. $\delta_{\mathrm{cm}}$ reaches 3 times the level of the as-cast counterpart.

Both results, the ranking of Var, a versus Var. b and the beneficial effect of solutioning, suggest that interdendritic segregation is an important factor'. Reducing the degree of interdendritic segregation, either by chemical modification or heat treatment, apparently leads to improved hot-tearing resistance. In fig. $2 a$, the as-cast microstructure of Var. $b$ is depicted showing in fact a remarkably homogeneous appearance with an eutectic content of less than $2 \%$. In contrast, the eutectic content of Var. a and IN792, which is known for its cracking propensity, is about $5 \%-6 \%$ (tab. II).

\footnotetext{
'For all tested materials, the level of interstitial segregants has been carefully monitored and kept at comparable level to exclude tramp element effects an the propensity to grain boundary cracking
}
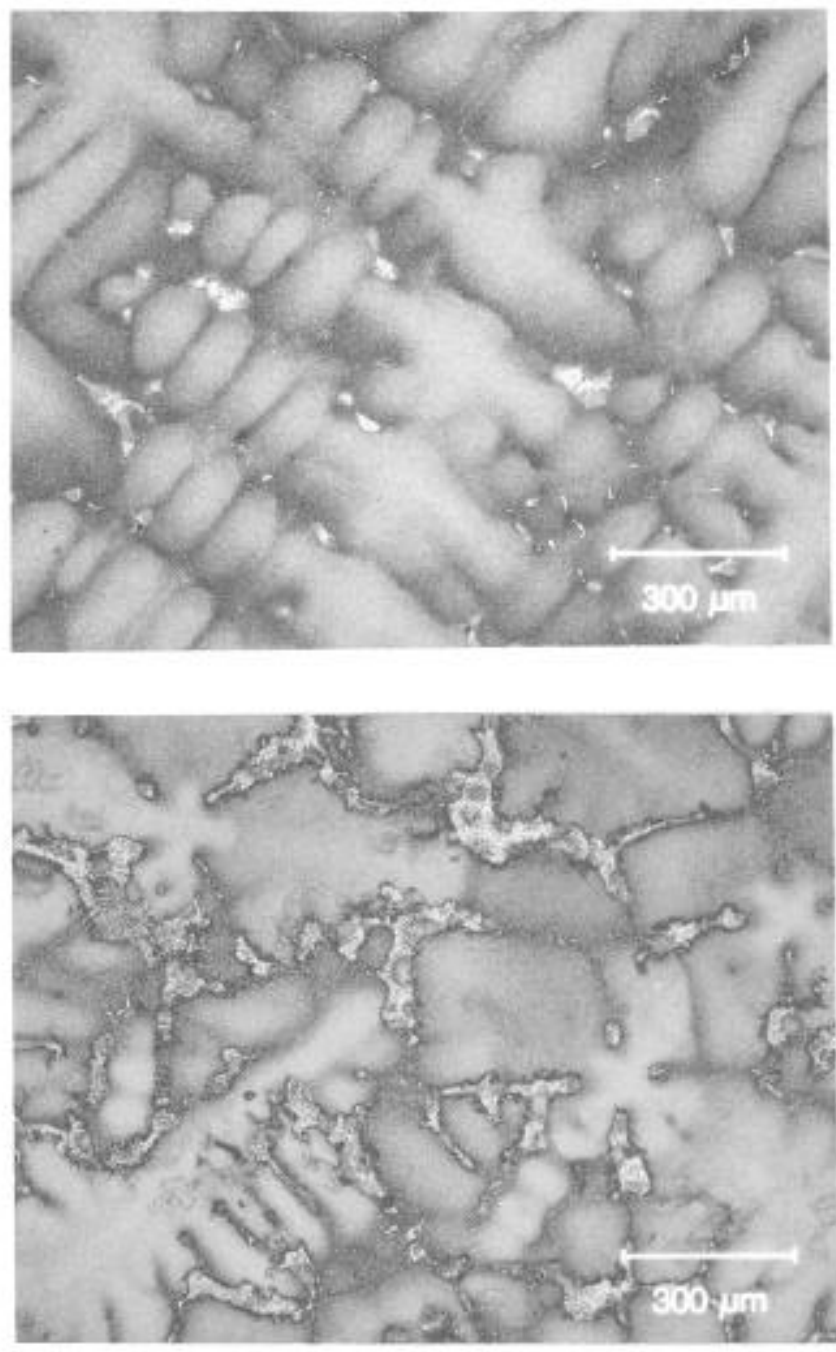

b

Figure 2a,b: As-cast microstructure of Var. b (a) in comparison to the as-cast microstructure of CM247LC DS (b), representing $\mathrm{Hf}$-containing alloys. 
The role of segregation may be best understood by noting that acceptable ductility, at temperatures ciose to the melting point, requires

- Homogeneous deformation over a large material volume fraction

- High intrinsic ductility of the volume element undergoing deformation

Alloys with high amount of interdendritic segregants promote strong melting point gradients from dendrite core to the last liquid to solidify. This in turn causes a strong gradient in homologous temperature $T / T_{m i}$ ( $T_{n}$; local melting point) and, hence, localization of creep deformation. It also increases the likelihood of remaining liquid pools which can be separated by shrinkage strains and act as crack initiation sites. Thirdly, high amounts of interdendritic segregants increase the volume fraction of eutectic islands at grain boundaries which also appear to be preferential fracture sites (fig. 3 ) because they lead to additional strain localization and/or reduced ductility. Therefore, it is concluded that for Hf-free DS-alloys the amount of eutectic forming elements (i.e. interdendritic segregants) should be as low as possible to meet the above requirements.

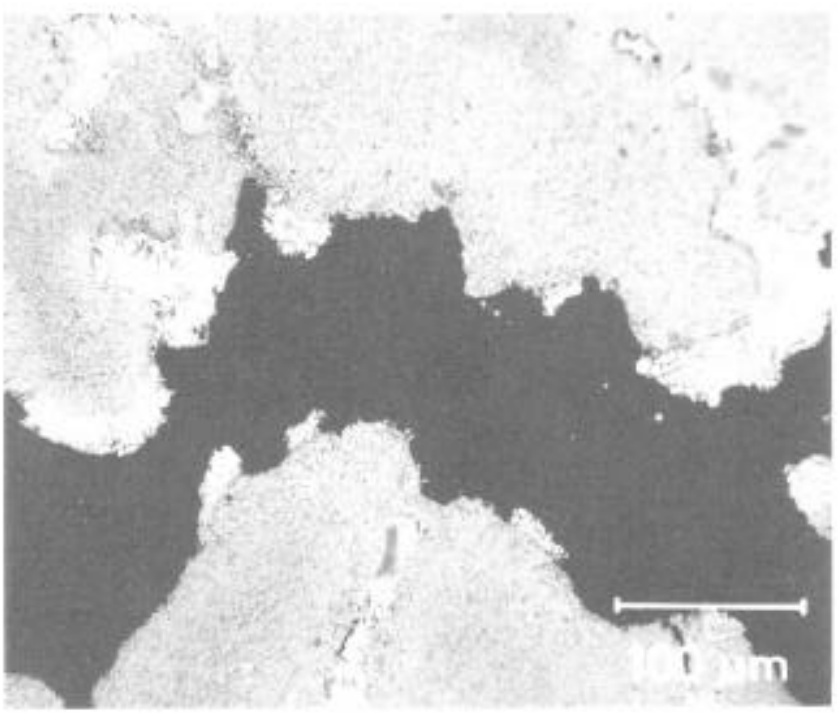

Figure 3: Microsection through a grain boundary crack of Var a

Although discussion of the Hffeffect is beyond the scope of this paper, it is noted that Hf-containing materials often form relatively broad eutectic regions rather than islands at grain boundaries (fig. 2b). Because the total shrinkage strain can then be distributed over a relatively large volume fraction of almost constant melting point, the beneficial effect of $\mathrm{Hf}$ when added in sufficient quantity is plausible. Prerequisite is, however, that the eutectic region is sufficiently ductile. To achieve this latter requirement in non- $\mathrm{Hf}$ containing materials is probably difficult due to the potential embrittling effect of $\mathrm{Ti}$ and $\mathrm{Ta}$ at levels necessary to promote sufficiently high eutectic volume fractions
To cross-check the Gleeble results, blades of different size and complexity have been cast in Var. a, b. CM247LC DS and IN792DS. The results are summarized in tab. II. They show that the casting results are consistent with the ranking suggested by fig. 1. Remarkably good results are achieved with the "lean" Var. b and the $\mathrm{Hf}$ containing material CM247LC. Examples of sound and cracked blades are given in fig. 4
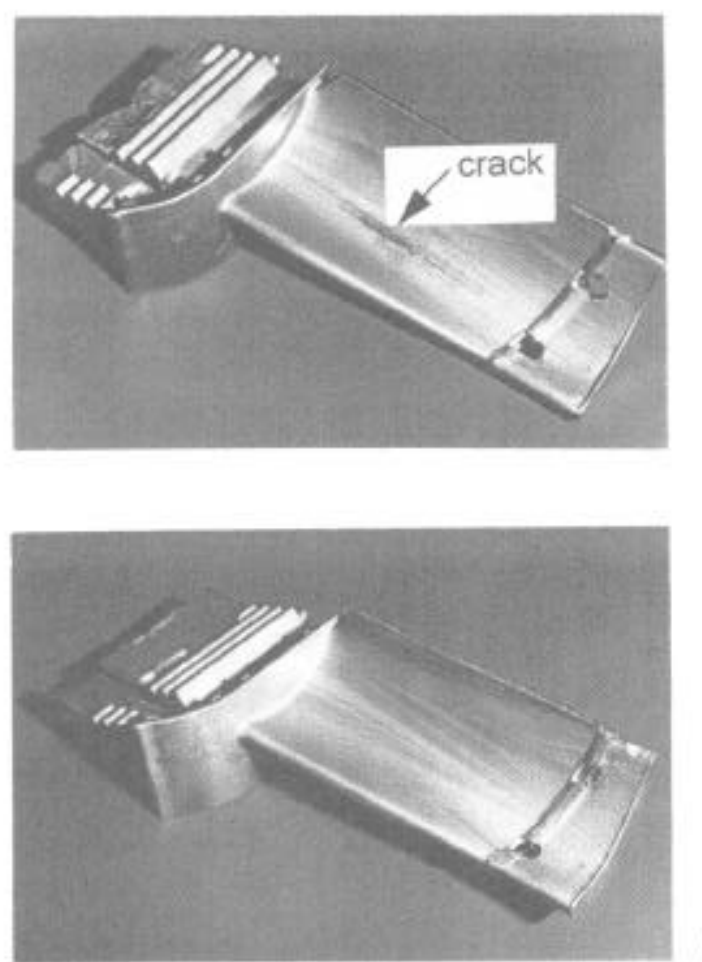

h

Figure $4 a, b: 270 \mathrm{~mm}$ test blade cast in Var. a (fig. a) and Var. b (fig. b). Note the absence of grain boundary cracking for Var. $b$.

\section{Freckle formation}

In addition to resistance against GB cracking, DS superalloys must have a high resistance against freckle formation. Freckles are defects that appear as elongated "chains" of equiaxed grains with high eutectic phase content caused by strong enrichment in $\mathrm{Ti}, \mathrm{Ta}$, and $\mathrm{Hf}$ (fig. 5). Their formation is attributed to the flow of interdendritic liquid $/ 2,3,6 /$ which is driven by an instable density distribution (interdendritic liquid lighter than liquid with nominal composition). It is a phenomenon that is dependent on casting condition and alloy chemistry /3/. Long solidification times do promote freckle formation. Hence, it is of particular importance for the production of large, industrial gas turbine parts to select freckle-resistant DS-alloys. 
Table II Assessment of alloy sensitivity to grain boundary cracking for two model compositions and two commercially available alloys. Results from Gleeble experiments are given as ranking (1: best; 3 worst). Comparison is made to the average $\gamma / y^{\prime}$-eutectic content in the as-cast condition.

\begin{tabular}{|l|l|l|l|l|l|}
\hline \multicolumn{1}{|c|}{ Alloy } & \multicolumn{1}{|c|}{$\begin{array}{c}\text { Gleeble } \\
\text { ranking }\end{array}$} & \multicolumn{1}{c|}{$\begin{array}{c}\text { DS-blade } \\
220 \mathrm{~mm}\end{array}$} & $\begin{array}{c}\text { DS-blade } \\
270 \mathrm{~mm}\end{array}$ & $\begin{array}{c}\text { DS-blade } \\
350 \mathrm{~mm}\end{array}$ & $\begin{array}{l}\gamma / \text {-eutectic } \\
\text { content (\%) }\end{array}$ \\
\hline Var a & 3 & sound & cracks & cracks & 5 \\
\hline Var b & 1 & sound & sound & sound & 1.5 \\
\hline IN792 & - & cracks & cracks & cracks & 6 \\
\hline CM247LC & 2 & sound & sound & sound & 8 \\
\hline
\end{tabular}

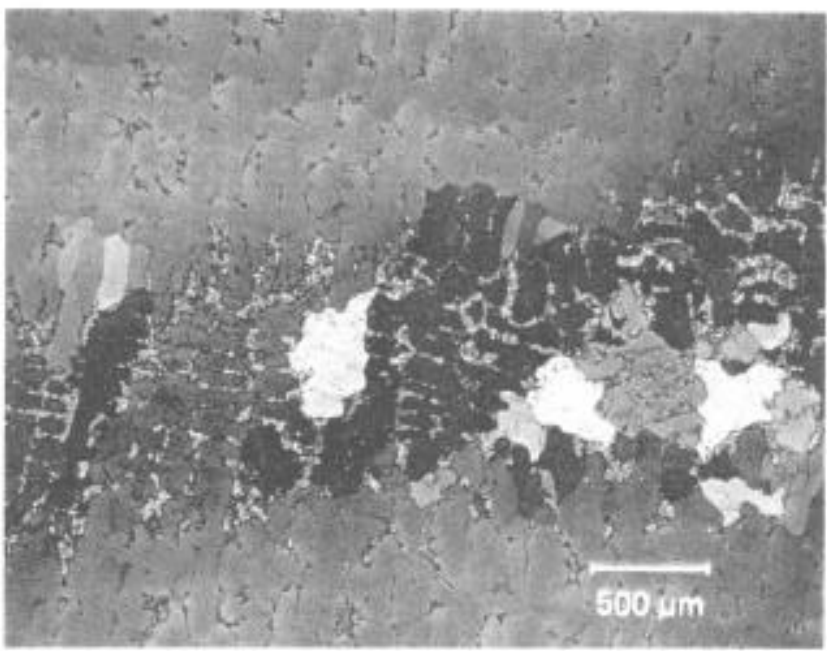

Figure 5: Freckle defect in a DS casting (longitudinal section). Equiaxed grains and a strong enrichment in the eutectic phase are visible.

Absence of freckle formation regardless of the casting condition is expected for alloys where the interdendritic liquid exhibits a higher density, Pld. than the liquid with nominal composition, $\bar{\rho}$. This requires careful balance of elements that strongly partition to the dendritic or interdendritic regions $(\mathrm{W}, \mathrm{Ti}, \mathrm{Ta})$. While $\rho_{n}>\bar{\rho}$ may not be met for other reasons, the tendency to freckle formation must be considered as an important parameter within the overall alloy development strategy

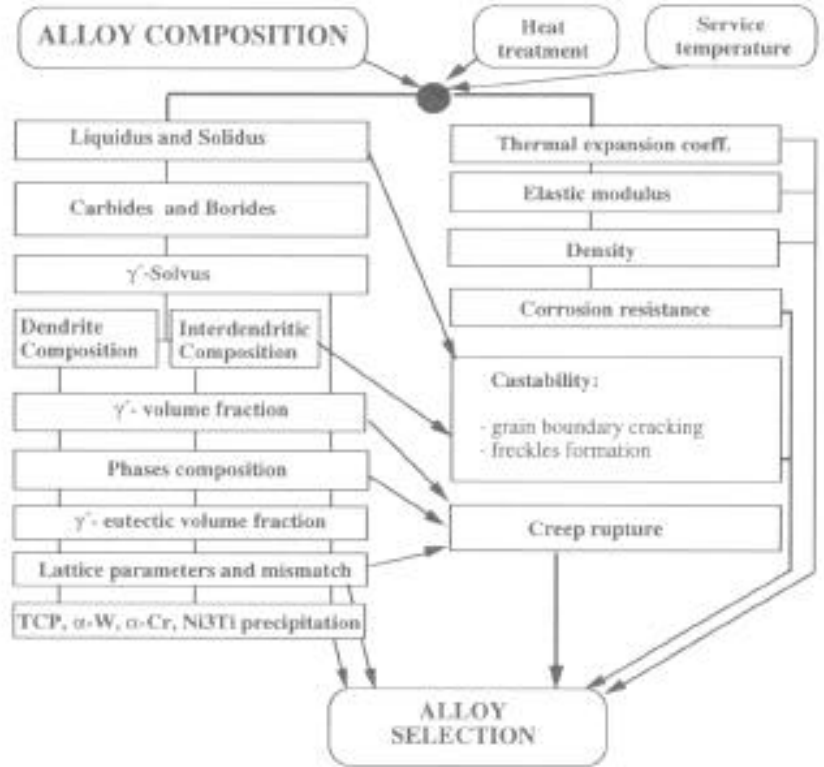

Fig 6: Computer software flow diagram showing the calculated properties.

To obtain quantitative information on freckle resistance, a software program (fig. 6) as described in detail elsewhere $17 /$ was used to calculate the partitioning of element i between dendritic and interdendritic volume:

$$
k=x_{i d} / x_{\text {id }}
$$

( $k$ : partitioning coefficient; $x_{\text {it. }} x_{\text {id }}$ weight fraction of element $i$ in dendrite core and interdendritic space respectively). Results obtained for Var, a and Var, b are shown in table III. 
Tab. III Calculated partitioning coefficients, $k_{i}$, for Var. a and Var. $b$. Also included is the liquid metal density, $\rho_{i}$, taken for further calculations.

\begin{tabular}{|l|l|l|l|l|l|l|}
\hline & $\mathrm{Cr}$ & $\mathrm{Co}$ & $\mathrm{W}$ & $\mathrm{Al}$ & $\mathrm{Ti}$ & $\mathrm{Ta}$ \\
\hline $\mathrm{k}_{\mathrm{i}, \text { Var. } \mathrm{a}}$ & 1.07 & 1.1 & 1.47 & 0.93 & 0.77 & 0.64 \\
\hline $\mathrm{k}_{\mathrm{i}, \text { Var. b }}$ & 1.09 & 1.1 & 1.44 & 0.95 & 0.75 & 0.64 \\
\hline$\rho_{\mathrm{i}}\left(\mathrm{g} / \mathrm{cm}^{3}\right)$ & 6.46 & 7.7 & 17.6 & 2.4 & 4.13 & 15.0 \\
\hline
\end{tabular}

Given the nominal composition, $\bar{x}_{i}$, and the dendritic volume fraction, $f_{d}, x_{i, i d}$ can be expressed as

$$
x_{i, i d}=\bar{x}_{i} /\left(f_{d}\left(k_{i}-1\right)+1\right)
$$

Assuming furthermore that the liquid behaves as an ideal solution, the solidification density coefficient, SDC, defined as the quotient between the density of the interdendritic liquid and the density of the liquid with nominal composition /8/, can be derived:

$$
\mathrm{SDC}=\sum_{\mathrm{i}} \rho_{\mathrm{i}} \mathrm{x}_{\mathrm{i}, \mathrm{id}} / \sum_{\mathrm{i}} \rho_{\mathrm{i}} \overline{\mathrm{x}}_{\mathrm{i}}
$$

( $\rho_{i}$ : density of pure element $i$ in the liquid state). It characterizes the tendency to freckle formation. As discussed above, absence of freckle formation is expected for SDC $>1$. Taking $f_{d}=0.45$ as typical value, "no-freckle" lines defined by SDC $=1$ are plotted in fig. 7 as a function of the $\mathrm{Ti}, \mathrm{Ta}$ and $\mathrm{W}$ content. The area to the right of each "iso-tungsten" line corresponds to chemical compositions that are predicted to be strictly freckle-safe. It is seen that Var. a and Var. b do not quite meet this criterion which means that further alloy optimization should take place, for instance substituting tungsten by tantalum. It is also noted that $\mathrm{a} \mathrm{Ta} / \mathrm{Ti}$ ratio $>1$ is required if tungsten levels in excess of $4 \mathrm{wt} . \%$ are added for strength reasons.

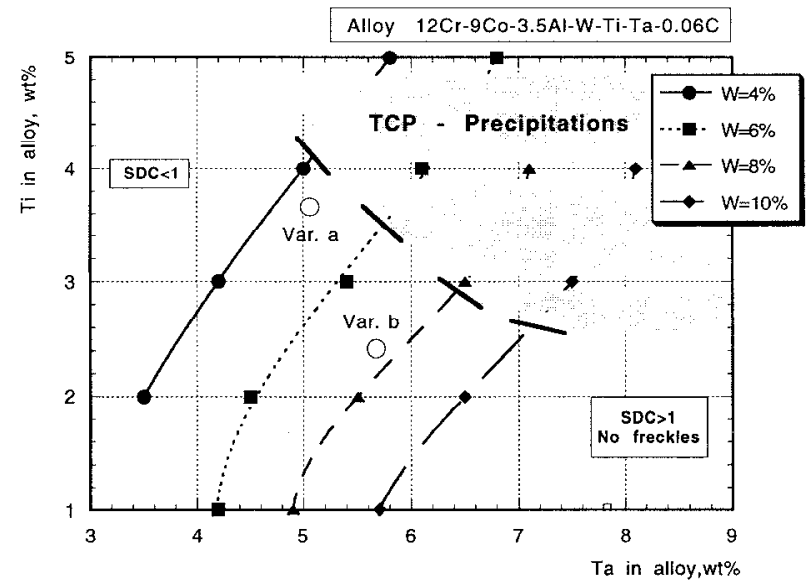

Figure 7: Plot of "no-freckle" lines (SDC = 1) in dependence of the $\mathrm{Ti}$ and $\mathrm{Ta}$ content for various tungsten levels. The boundary for TCP formation is also indicated.

\section{Heat treatment window and mechanical properties}

The ability to completely solution the $\gamma^{\prime}$-phase is an important factor to avoid weak links in the microstructure /9/ and to exploit the full strength potential of DSsuperalloys. For industrial applications, the heat treatment window should be at least $20 \mathrm{~K}$. This requirement is often not fulfilled using DS-versions of materials that were originally designed for conventional casting. Fig. 8a shows the differential thermal analysis (DTA) curve of IN792DS as example. It is noted that incipient melting starts at a temperature where $y^{\prime}$ dissolution is still ongoing. This problem is further aggravated in large DS-castings for industrial gas turbine applications since cooling rates are relatively low.
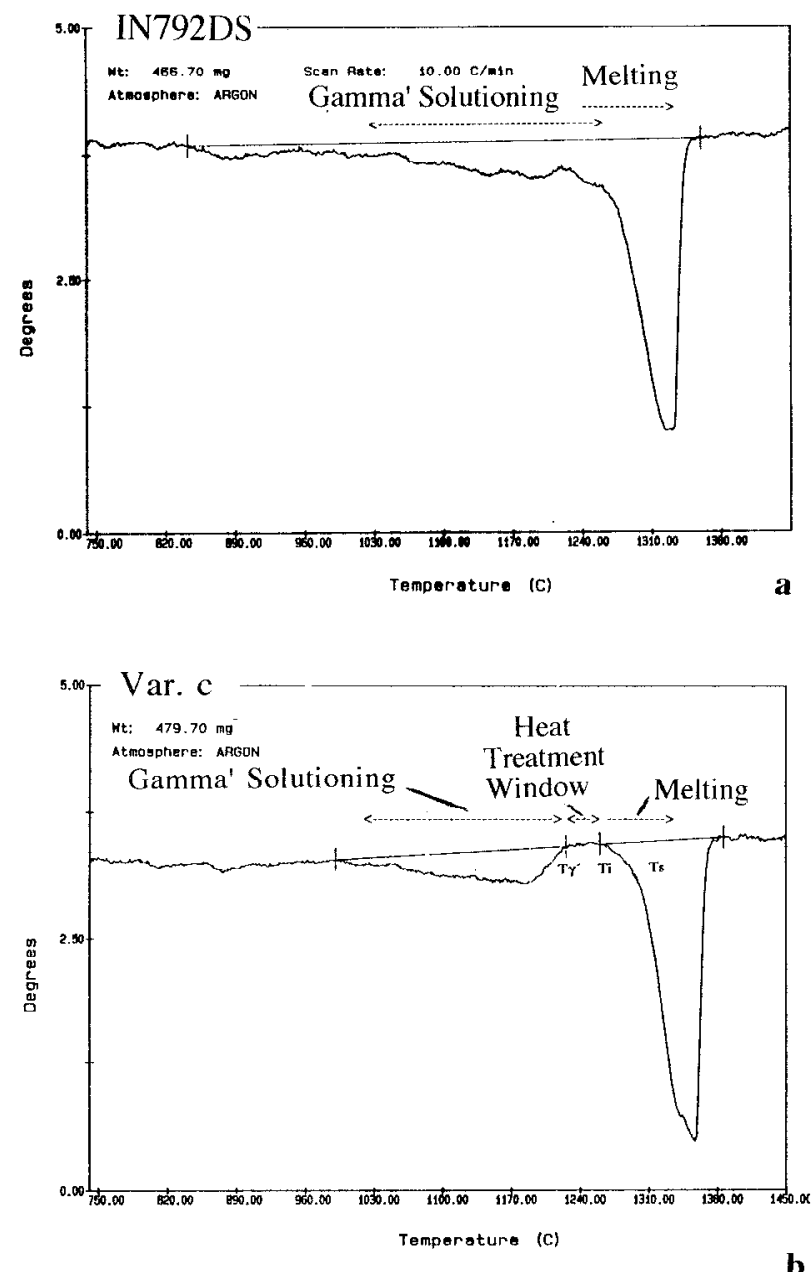

Figure 8a,b: Differential thermal analysis (heating rate: $10^{\circ} \mathrm{C} / \mathrm{min}$ ) of IN792DS (a) and Var. c (b). For Var. c, a heat treatment window of approximately $30^{\circ} \mathrm{C}$ between $\gamma$ solutioning and incipient melting is apparent. 
Table IV: Compilation of the composition and heat treatment window (HTW) for selected model alloys.

\begin{tabular}{|l|l|l|l|l|l|l|l|l|l||l|}
\hline Alloy & $\mathrm{Ni}$ & $\mathrm{Co}$ & $\mathrm{Cr}$ & $\mathrm{W}$ & $\mathrm{Al}$ & $\mathrm{Ti}$ & $\mathrm{Ta}$ & $\mathrm{B}$ & $\mathrm{C}$ & HTW $\left({ }^{\circ} \mathrm{C}\right)$ \\
\hline Var. c & bal. & 9.0 & 12.0 & 9.0 & 3.5 & 3.0 & 5.0 & 0.015 & 0.07 & 32 \\
\hline Var. d & bal. & 9.0 & 12.0 & 6.4 & 4.1 & 3.3 & 5.0 & 0.015 & 0.07 & $<0$ \\
\hline Var. e & bal. & 9.0 & 12.0 & 6.4 & 4.2 & 2.0 & 6.8 & 0.015 & 0.07 & 28 \\
\hline
\end{tabular}

In tab. IV, a number of model compositions are given for which the heat treatment window was measured by DTA (fig. 8b). Comparing Variants $d$ and $e$, it is apparent that replacement of $\mathrm{Ti}$ by $\mathrm{Ta}$ helps to enlarge the heat treatment window. For obvious reasons, it is also beneficial to replace $\gamma$-forming elements ( $\mathrm{Al}, \mathrm{Ti}, \mathrm{Ta}$ ) by refractory elements such as tungsten (compare Var. $c$ with Var. d)

Note, that the requirements for GB cracking resistance and acceptable heat treatment window point in the same direction, namely reduction of the alloy segregation level by formulation of "lean" compositions. It turns out that a $\mathrm{Ta} / \mathrm{Ti}$-ratio $>1.5$ along with a Ti-content $<3.5 \%$ is generally preferable. Although corrosion resistance tends to decrease with decreasing Ti-content, acceptable levels can still be maintained following these guidelines $/ 8 /$, especially since homogeneity adds to the environmental resistance. This strategy is quite different from previous alloy designs for stationary gas turbine applications where high Ti-contents at moderate Ta-levels were selected in the quest to maximize corrosion resistance.

\section{Experience with ABB 2 DS}

ABB 2 DS is an alloy that was developed along the lines discussed in the previous sections. The composition is derived from Var. $b$ with further modifications to ensure SDC $>1$. The typical composition range is given in $/ 10 /$. Important features are a relatively high $\mathrm{Ta} / \mathrm{Ti}$ - ratio $>1.5$ which was found to be necessary to achieve requirements on GB cracking resistance, freckle resistance and heat treatment window. Compared to conventional alloys such as IN738LC or IN792, the tungsten level of approx. $7.5 \%$ $9.5 \%$ is also relatively high. This was found to be beneficial from a strength point of view. In fig. 9, creep and fatigue properties are shown in comparison to IN738LC and CM247LC DS. Despite a Cr-content of approx. $12 \%, \mathrm{ABB} 2$ DS shows remarkably good properties. They are comparable to superalloys with significantly lower $\mathrm{Cr}$-content. The creep strength advantage over IN738LC is approx. $50^{\circ} \mathrm{C}$. This is partly attributed to the excellent heat treatment response of the alloy. For industrial applications, a two stage heat treatment turns out to be sufficient for complete solutioning (fig. 10).
Using a complex blade of approx. $300 \mathrm{~mm}$ length, the castability of ABB 2 DS was evaluated in comparison to state-of-the-art alloys (CM247LC , CM186LC). Results are summarized in tab $V$. It is noted that ABB 2 DS shows excellent castability. Despite the complexity of the blade, which is reflected in the GB cracking phenomenon observed for CM186LC DS, $100 \%$ casting yield based on standard defect acceptance criteria has been achieved on a statistically significant number of parts. Very good castability is also observed for CM247LC DS. Freckles are generally shallow and can be machined off. On the one hand, this result confirms the excellent castability of CM247LC DS in stationary gas turbine applications. On the other hand, it demonstrates that DS-castable compositions can successfully be formulated in the $12 \%$ Cr range.

Table V: Summary of the casting results for three DSalloys (n.e.: not evaluated).

\begin{tabular}{|l|c|c|c|}
\hline & ABB 2 DS & $\begin{array}{c}\text { CM247LC } \\
\text { DS }\end{array}$ & $\begin{array}{c}\text { CM186LC } \\
\text { DS }\end{array}$ \\
\hline GB cracking & No & No & Yes \\
\hline Equiaxed grains & No & No & n.e. \\
\hline Freckles & No & Yes & n.e. \\
\hline
\end{tabular}



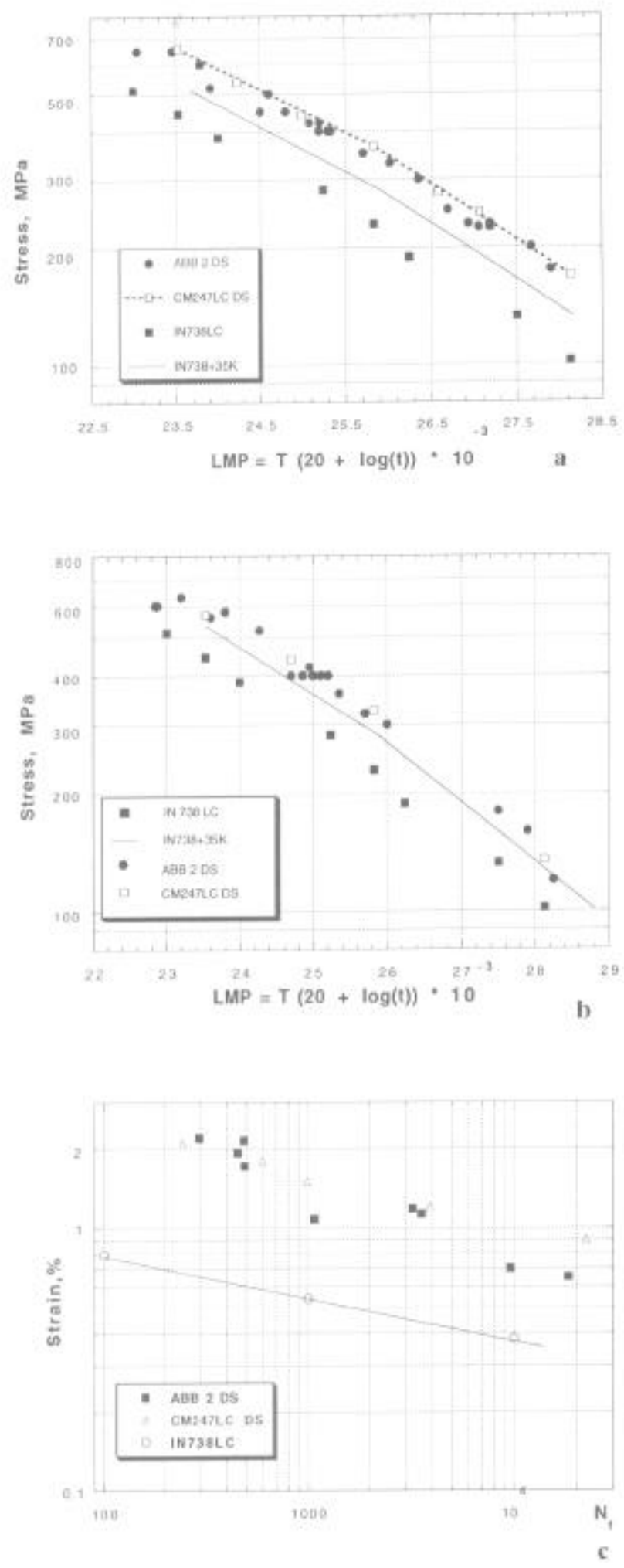

Figure 9a-c: Mechanical properties of ABB 2 DS in comparison to IN738LC and CM247LC DS.
a, b. Longitudinal (a) and transverse (b) creep strength
in Larson-Miller representation.
c. LCF data in longitudinal direction at $850^{\circ} \mathrm{C}$.

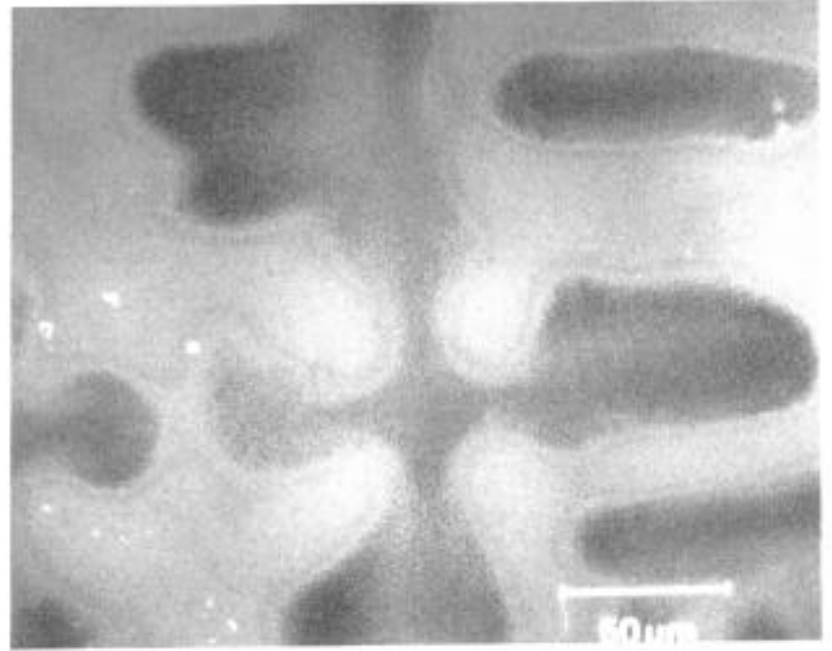

Figure 10: Microstructure of ABB 2 DS after solutioning at $1220^{\circ} \mathrm{C} / 2 \mathrm{~h}, 1240^{\circ} \mathrm{C} / 2 \mathrm{~h}$

\section{Conclusions}

Fundamental aspects of DS-castability were investigated with emphasis on $\mathrm{Hf}$-free compositions. It was concluded that the amount of interdendritic segregants has to be reduced to improve resistance against grain boundary cracking and to enlarge the heat treatment window. Furthermore, a new parameter, the solidification density coefficient SDC, has been proposed to describe the freckle resistance of DS-alloys quantitatively. The excellent performance of alloy ABB 2 DS in terms of castability and high temperature strength is taken as evidence for the validity of the concepts discussed here.

\section{Acknowledgment}

Part of this work was sponsored under the Swiss Priority Program for Materials. The authors would also like to thank Prof. J.J. Chene and Dr. H. Guo for stimulating discussions and the performance of the Gleeble experiments. 


\section{References}

/1/ D.N. Duhl and C.P. Sullivan, "Some Effects of Hafnium Additions on the Mechanical Properties of a Columnar-grained Nickel-base Superalloy," Journal of Metals, (July 1977), 38.

12/ M.C. Flemings and G.E: Nereo, Trans. Met. Soc. AIME, 212 (1967), 1449

13/ T.M. Pollock et al., "Grain Defect Formation during Directional Solidification of Nickel Base Single Crystals," Superalloys 1992, ed. S.D. Antolovich et al. (Warrendale, PA, The Metallurgical Society, 1992), 125.

14/ M.R. Winstone, J.E. Northwood, "Structure and Properties of Directionally Solidified Superalloys in Thin Sections," Solidification Technology in the Foundry and Cast House (Coventry, England: The Metals Society, 1980), 298.

15/ J.-J. Chene and H. Guo, "Characterization of Hot Ductility Behavior of Directionally Solidified Superalloys," Materials Research for Engineering Systems (Bern, Switzerland: Technische Rundschau, 1994), 20.

16/ C.T. Sims, N.S. Stoloff and W.C. Hagel, eds., Superalloys II (New York, USA: John Wiley \& Sons, 1987), 193.

17/ M. Konter, "Computer Aided and Experimental Development of Superalloys for Gas Turbines," Ph.D. Thesis, CNIITMASH, Moscow, 1992.

/8/ J. Rösler and M. Konter, "Development of a High Strength Corrosion Resistant DS Superalloy," Materials for Advanced Power Engineering (Netherlands: Kluwer Academic Publishers, 1994), 1213.

19/ P. J.-L. Meriguet, eds., Advanced Blading for Gas Turbines, COST501, Round II, Work Package 1 (Brussels, Belgium: European Commission, 1995), 61.

/10/ J. Rösler, DE Patent File 4,323,486 A1, BRD. 